\section{Peroral Cholecystoscopy with a Shape-Memorizing Alloy Catheter}

For the purpose of improving the ease and reliability of catheter insertion into the cystic duct and gallbladder $(1-3)$, we developed a new combination method utilizing an ultrathin fiberscope (miniscope, $0.8 \mathrm{~mm}$. Olympus), a guide wire ( 0.25 inches) and a shapememorizing alloy-bending catheter (SMA catheter, $2.6 \mathrm{~mm}$, Olympus). The total length of the SMA catheter is $2,245 \mathrm{~mm}$, and the effective length is $1,969 \mathrm{~mm}$. The external diameter of the tip is $2.6 \mathrm{~mm}$, and the diameter of the working channel is $1.2 \times 2.2 \mathrm{~mm}$. The tip ( $20 \mathrm{~mm}$ diameter) is made of a flexible material and can bend to an angle of 90 degrees in two directions. The combination of the SMA catheter with guide wire and a miniscope has the following advantages: the opening of the cystic duct can be directly observed and confirmed; a guide wire can be inserted under direct Vision: and the catheter can be inserted beyond tortuous parts of the cystic duct by utilizing its bending function. In addition, insertion of the catheter into the gallbladder provides a method for adjusting and bending miniscopes which do not themselves have these functions (4), thus improving endoscopic observation. The disadvantages of this catheter include difficulty in insertion in patients other than sphincterotomy cases due to its relatively large diameter and soft tip. Although the SMA catheter requires some improvement, this combination method should afford new diagnostic and therapeutic approaches to gallbladder disease.

\section{K. Yamao, S. Nakazawa, J. Yoshino, K. Imai, N. Kanemaki,}

M. Fujimoto

Department of Internal Medicine, Second Teaching Hospital, Fujita Health University School of Medicine, Nagoya, Japan

\section{References}

1. Foerster EC, Auth J, Runge U, et al.: ERCG; endoscopic retrograde catheterization of the gallbladder. Endoscopy 1988; 20: $30-33$.

2. Miller GL. Laurence BH, MaCarthy .H: Cannulation of the cystic duct and gallbladder. Endoscopy 1989; 21: 223-224.

3. Soehendra N, Schluz H, Nam VC, et al.: ESWL and gallstone dissolution with MTBE via a naso-vesicular catheter. Endoscopy $1990 ; 22: 176-179$.

4. Foerster EC. Schneider MU, Matek $W$. et al.: Transpapillary cholecystoscopy. Endoscopy 1989;21:381-383.

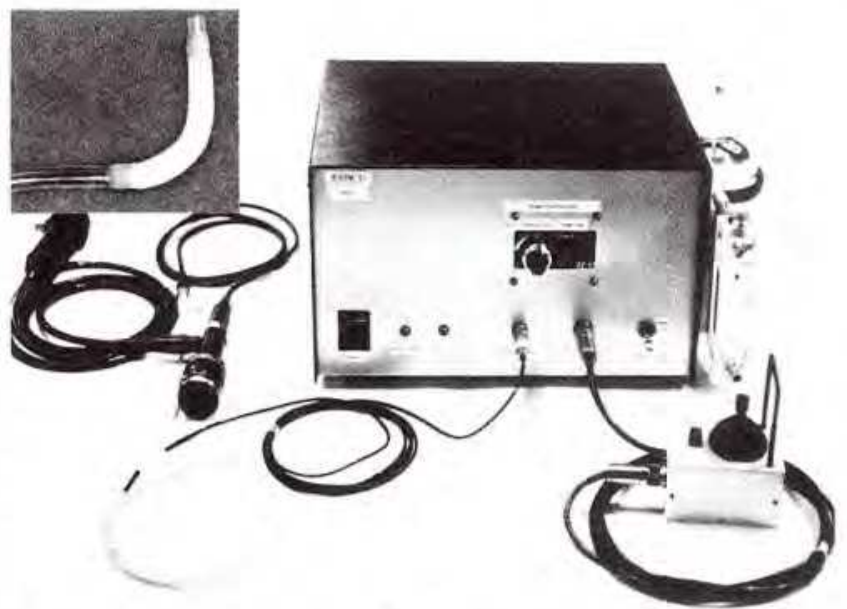

Figure 1: SMA catheter system. The tip of the SMA catheter (upper left) is in the bent position of the flexible tip which was obtained by heating.

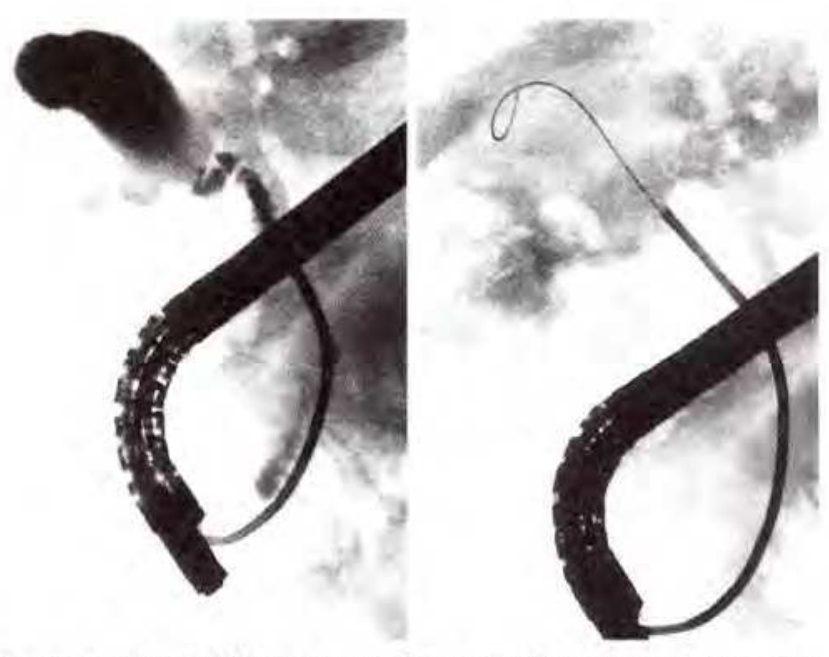

Figure 2: a The SMA catheter was first inserted into the cystic duct under direct vision using a miniscope. $b$ Then the guide wire was inserted into the gallbladder. The SMA catheter was inserted into the gallbladder with the aid of the guide wire.

Corresponding Author

K. Yamao, M.D.

3-6-10 Otobashi, Nakagawa-ku,

Nagoya, Japan

Fax No: (052) 3229886 